\title{
Save the Hip-Hip Surveillance in Cerebral Palsy is the Need of the Hour!!
}

\author{
Ashok N. Johari ${ }^{1}$ \\ C Indian Orthopaedics Association 2021
}

India with a population of 1.3 billion has a $0.3 \%(2.95 / 1000$ children) pooled prevalence of cerebral palsy [1]. Whilst the exact prevalence data is unavailable, it is largely believed that we have at least 2.5 million people with cerebral palsy.

Children with cerebral palsy have a definite incidence of displacement of a hip. Earlier publications on the subject show an incidence of hip displacement of 35\% with $15 \%$ hips dislocating [2-4]. Against the backdrop of 2.5 million Indians affected, the prevalence of this problem could be safely estimated to be over 8 lacs. Hip displacement is usually silent till it becomes symptomatic. Most patients become symptomatic, lose function, and caregivers have increasing difficulties with progressive hip displacement. Migration of the hip causes changes in the upper femur, specifically the femoral head and the acetabulum. Pain is a late symptom suggesting cartilage damage, an inflammatory response and sensitization of nociceptor terminals in the hip. It increases in severity and frequency with worsening morphology of the hip affecting the health-related quality of life. Reconstruction of the hip at this stage gives a much inferior result when compared to early proactive management of hip instability [5]. In still more advanced stages, reconstruction of the hip is not possible and salvage procedures done for pain relief, e.g., femoral head resection, have many complications and poor outcomes [6].

The incidence of hip displacement has a linear relationship to the GMFCS (Gross Motor Function Classification System) with the non-ambulatory (GMFCS IV and V) having the most marked change in the anatomy and higher speed and grades of displacement of 69-90\% [2, 4]. These patients form a large pool (22.3-36.1\%) of cerebral palsy patients [7] and are the most vulnerable to symptomatic hip instability. Whilst hip pathology is at its highest in GMFCS levels IV

Ashok N. Johari

drashokjohari@hotmail.com

1 Paediatric Orthopaedics, B. Nanavati Super Specialty Hospital, Mumbai, India and $\mathrm{V}$, it is also prevalent to a significant degree in marginal ambulators, e.g., GMFCS II and III to an extent of $15-40 \%$ [4]. This demands that the problem be detected much before it becomes symptomatic and hence there is a distinct need for early detection and prevention of the progress of hip pathology. With this realization, hip surveillance is a logical next step in the care pathway for our patients. Hip migration can be easily documented and followed on serial X-rays by the Reimer's migration index [8].

Large, population-based hip surveillance programmes, started in 1994 with the Swedish Surveillance Program followed by the Australian state programs in 1997. The Swedish Group reported their 10- and 20-year experience [3, 9]. Their data showed a definite reduction of hip dislocation in their study pool with a $0 \%$ incidence in their last cohort between 1998 and 2007. The Australian experience has been similar with an increase in the number of preventive surgeries mainly in the form of soft tissue releases but these lesser magnitude surgeries very often helped to prevent or delay the final reconstructive surgery. The need for salvage surgery for hip dislocation was eliminated [10].

Hence the need of the hour for the developing world is surveillance. Compared to the developed nations, our problems are those of a completely decentralized health care which lacks a system and works mainly in a reactive mode, physician and patient ignorance, socioeconomic problems, long distances and remote corners of the country to cater to! With the many challenges, formulating a national surveillance program with access to therapeutic care seems impossible! But start we must, with no thought of perfection. Voluntary and societal efforts must be taken to a governmental level to be enforced as a health policy. With cooperation and collaboration of all stake holders we are striving to create a hip surveillance program for our cerebral palsy patients with the National CP Hip Surveillance-Save The Hip Project. A definite fall out of this will be surveillance for the spine. A lot of advocacy and action will be required to percolate this philosophy to the classes and masses for the better health of 
our patients with cerebral palsy! Working on this need of the hour is our only hope of saving those hips!

\section{Compliance with Ethical Standards}

Conflict of interest The authors declare that they have no conflict of interest.

Ethical standard statement This article does not contain any studies with human or animal subjects performed by the any of the authors.

Informed consent For this type of study, informed consent is not required.

\section{References}

1. Chauhan, A., Singh, M., Jaiswal, N., Agarwal, A., Sahu, J. K., \& Singh, M. (2019). Prevalence of Cerebral Palsy in Indian Children: A Systematic Review and Meta-analysis. Indian Journal of Pediatrics, 86(12), 1124-1130. https://doi.org/10.1007/s1209 8-019-03024-0 (Epub2019Jul13).

2. Hägglund, G., Lauge-Pedersen, H., \& Wagner, P. (2007). Characteristics of children with hip displacement in cerebral palsy. BMC Musculoskeletal Disorders, 8, 101.

3. Hägglund, G., Andersson, S., Düppe, H., Lauge-Pedersen, H., Nordmark, E., \& Westbom, L. (2005). Prevention of dislocation of the hip in children with cerebral palsy. The first ten years of a population-based prevention programme. Journal of Bone and Joint Surgery (British Volume), 87, 95-101.

4. Soo, B., Howard, J. J., Boyd, R. N., et al. (2006). Hip displacement in cerebral palsy. Journal of Bone and Joint Surgery (American Volume), 88, 121-129.

5. Wawrzuta, J., Willoughby, K. L., Molesworth, C., Ang, S. G., Shore, B. J., Thomason, P., \& Graham, H. K. (2016). Hip health at skeletal maturity: a population-based study of young adults with cerebral palsy. Developmental Medicine and Child Neurology, 58, 1273-1280.

6. Kolman, S. E., Ruzbarsky, J. J., Spiegel, D. A., \& Baldwin, K. D. (2016). Salvage Options in the Cerebral Palsy Hip: A Systematic Review. Journal of Pediatric Orthopaedics, 36, 645-650.

7. Reid, S. M., Carlin, J. B., \& Reddihough, D. S. (2011). Using the Gross Motor Function Classification System to describe patterns of motor severity in cerebral palsy. Developmental Medicine and Child Neurology, 53, 1007-1012.

8. Reimers, J. (1980). The stability of the hip in children. A radiological study of the results of muscle surgery in cerebral palsy. Acta Orthopaedica Scandinavica, 184(1), 1-100.

9. Hagglund, G., Alriksson-Schmidt, A., LaugePedersen, H., et al. (2014). Prevention of dislocation of the hip in children with cerebral palsy: 20-year results of a population-based prevention programme. Bone and Joint Journal, 96-B, 1546-1552.

10. Dobson, F., Boyd, R. N., Parrott, J., Nattrass, G. R., \& Graham, H. K. (2002). Hip surveillance in children with cerebral palsy: impact on the surgical management of spastic hip disease. Journal of Bone and Joint Surgery [British Volume], 84-B, 720-726.

Publisher's Note Springer Nature remains neutral with regard to jurisdictional claims in published maps and institutional affiliations. 